\title{
TRAFFIC AND FLIGHT GUIDANCE DEPICTION ON A SYNTHETIC VISION SYSTEM DISPLAY: THE EFFECTS OF CLUTTER ON PERFORMANCE AND VISUAL ATTENTION ALLOCATION
}

\author{
Christopher D. Wickens, Amy L. Alexander, William J. Horrey, Ashley Nunes and Thomas J. Hardy \\ University of Illinois, Aviation Human Factors Division
}

Savoy, Illinois

\begin{abstract}
Fourteen pilots flew a synthetic vision system (SVS) display, through a terrain and traffic-rich environment in a high fidelity flight simulator. Traffic information was hosted on the SVS display. In a $2 \times 2$ factorial design, the SVS display hosted a highway-in-the-sky in half the conditions, and hosted an instrument panel overlay in the other half. We examined the effects of the resulting clutter from overlay (but reduced scanning) on routine flight performance, SVS traffic detection, and response to off-normal events, as these were mediated by visual scanning measures of attention allocation. The tunnel greatly improved flight path tracking and traffic detection, but slightly disrupted the detection of unexpected outside world traffic. The instrument panel overlay provided no benefits to tracking and a clutter-related time cost to SVS traffic detection. Visual attention was focused on the SVS display over half the time, and rarely on the outside world, even in visual meteorological conditions (VMC), a source of possible cognitive tunneling.
\end{abstract}

\section{INTRODUCTION}

Synthetic Vision Systems provide pilots with a realistic 3D image of the terrain in front of the aircraft, with a primary objective of increasing terrain awareness, and reducing the likelihood of CFIT accidents (Schnell, Kwon, Merchant, \& Etherington, 2004; Prinzel Comstock, Glaab, Kramer, Arthur, \& Barry, 2004). As shown in Figure 1 (upper left panel), within the 3D ego-referenced SVS pictorial display, it is reasonable to consider designs that might also host three additional forms of information: (1) 3D information regarding the forward flightpath, in the form of a pathway, tunnel, or "highway-in-the-sky" (Beringer, 2000; Fadden, Ververs \& Wickens, 2001, Williams, 2002, Alexander, Wickens, \& Hardy, 2003), (2) information about traffic near the forward flightpath (Merwin, 1998), and (3) other aspects of the primary flight display, represented as a head-up display (HUD) -like overlay (Fadden et al., 2001).

All three of these design decisions--to implement a tunnel for guidance, to overlay traffic, and to overlay instruments-have implications for the pilots' allocation of attention and multi-task performance. At the one extreme, if all three elements are overlaid (tunnel, instrument panel, traffic depiction), a compact, but cluttered display will result. This should minimize the scanning and information access effort required to monitor all displays, but may inhibit the processing of fine detail because of the inhibitory effects of overlay clutter (Wickens, 2000; Kroft \& Wickens, 2003; Fadden et al, 2001). At the other extreme, a spatially-dispersed display will be created, challenging visual attention allocation, but reducing clutter.

In a full-mission simulation, we examined the implications of the tradeoff between the factors of clutter and spatial dispersion, contrasting the presence or absence of a tunnel, and the presence or absence of instrument panel overlay. Forward traffic was presented on a head-down SVS display in all four conditions created by orthogonally combining these two factors.
The assessment of which display configuration is optimal is complicated by the fact that such a system is intended to support a variety of tasks, and these may trade off with each other across different designs. For example, routine flightpath tracking is well supported by the tunnel (e.g., Fadden et al., 2001; Schnell et al., 2003; Prinzel et al., 2004), but flightpath tracking may sometimes be inhibited by the added clutter of overlay on the display (Fadden et al., 2001). Traffic detection may be supported by the reduced scanning of overlay (Fadden et al, 2001), but could be inhibited in this condition by the clutter caused by this overlay, particularly if traffic is not salient (Wickens, Ververs, \& Fadden, 2004; Yeh, Merlo, Wickens, \& Brandenburg, 2003).

Finally, while both flightpath control and traffic detection represent relatively "routine" aspects of performance, we are also interested in how the different display configurations influence the allocation of attention (measured by visual scanning) as this allocation may, in turn, influence the awareness of and response to three "off-normal" events (Foyle \& Hooey, 2003): (1) the detection of a "rogue aircraft", visible in the outside world, but not "known" by the image-generation system that is depicting traffic on the Cockpit Display of Traffic Information (CDTI) and SVS display (Wickens Helleberg \& Xu, 2002) (2) a ground-based antenna, and (3) the awareness of a runway offset, in which the SVS display guides the pilot to a landing which is offset from the location of the true runway. In all of these cases, we hypothesize that the "compellingness" of the SVS and tunnel might cause an undue attraction of visual attention (Olmos Wickens \& Chudy, 2000), to the benefit of routine flight control and the possible benefit of detecting SVS-located traffic, but to the detriment of off-normal event detection in which information was only available in the outside world. In the current research we identify "compellingness" and other aspects of visual attention control via measures of visual scanning. 

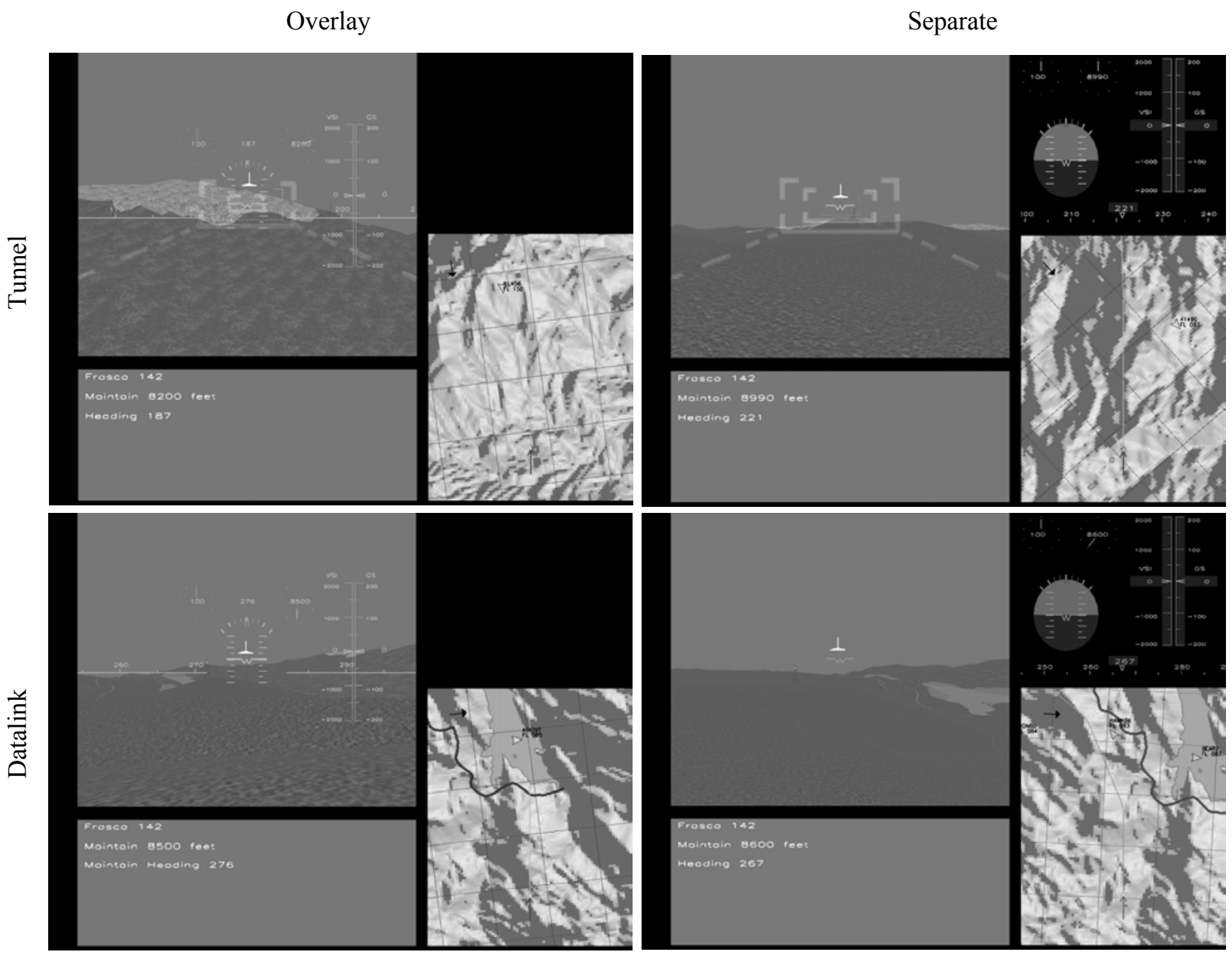

Figure 1: Four display suites: Left column: overlay. Right column: separate. Top row: tunnel. Bottom row: datalink.

\section{Participants}

METHOD

Fourteen instrument-rated pilots flew 8 experimental scenarios of 8-10 minutes each, involving a curved step-down approach, through a terrain-challenged region, to a simulated airport in Yosemite County, California. A Frasca twin-seat flight simulator with 180 degrees outside visual depiction was used.

\section{Displays}

The four different display suites are shown in Figure 1. The two suites on the top row ("tunnel") provided flightpath guidance via the preview of a 3D tunnel-in-the-sky, a depiction of ownship, and a 3D predictor of ownship 5 seconds into the future. Guidance for the two suites without the tunnel (bottom row) is provided by datalink (uplinked) instructions in the bottom box, which offer in verbal/numeric form the identical guidance information offered by the tunnel (e.g., a commanded heading and rate of climb or decent). Pilots could monitor their lateral course via the navigation display on the lower right as well as by reference to the instrument panel (upper right), showing heading; they could monitor vertical course with a vertical situation display (VSD; on the right side of the instrument panel), which depicted vertical deviation (and deviation rate) relative to the commanded flightpath.

The two display suites in the left column (overlay) are distinguished from those in the right (separate) in terms of whether or not the instrument panel was overlayed on the SVS display. In all four conditions, the SVS display contained terrain, an indicator of ownship's current position and instantaneous attitude relative to the terrain, a 5-second predictor, and traffic near the forward path (i.e., within the geometric field of view (GFOV) of the SVS display). Traffic consisted of blimps that did not translate across the map. In all conditions, the navigational display depicted the 2D command flightpath, ownship's current location and velocity vector, and, serving as a CDTI, all traffic in the surrounding airspace (except the rogue airplane described below).

\section{Procedures and Tasks}

Pilots were instructed to follow the guidance as accurately as possible to the landing. On half the approaches, low-visibility (instrument meteorological conditions--IMC) were encountered after the first leg until the final approach to the runway. One of the four approaches within each visibility condition, was flown with each of the four display suites. 
Thus, each display condition was replicated in IMC and VMC. While flying, pilots were instructed to detect with a verbal report any new traffic that became visible on the SVS display, and report any changes to traffic altitude that they noticed on either the SVS display or the NAV display (host to the CDTI). On the 3D SVS display, these changes appeared as analog changes in the height of the blimp. On the NAV display, they appeared as changes in the digital datatag.

Each pilot encountered each of the following off-normal events (each on a separate approach): (a) a "rogue aircraft" blimp (VMC only) that was only visible in the outside world, and positioned close enough to the commanded flightpath that a maneuver would be required to maintain separation; (b) a ground-based radio antenna, visible in the outside world and, like the rogue aircraft, in a position which would also induce a maneuver; (c) a runway offset (tunnel conditions only), in which both the tunnel and the SVS display provided guidance to an approach that was offset from the true runway, as the latter could be viewed in the outside world. Pilots were not pre-warned of these off-normal events. Thus, detection of and response to both the rogue airplane and the runway offset would be hindered to the extent that the tunnel induced an attentional tunneling to the SVS display at the expense of outside scanning.

Eight of the 14 pilots wore an ASL eye and head tracking system, so that direction of gaze toward different areas of interest could be established, and measured as a percent dwell time (PDT).

\section{RESULTS}

\section{Flightpath Tracking}

Flight control measures of deviations from the ideal flightpath revealed significant benefits of the integrated tunnel (relative to the separated sources of information from datalink guidance) for both vertical tracking (25 meter benefit; $\underline{F}(1,13)$ $=32.4, \mathrm{p}<.01)$ and lateral tracking $(20$ meters; $\mathrm{F}(1,13)=$ $96.5, \mathrm{p}<.01)$. The overlay of the instrument panel on the SVS produced a small (5 meter) benefit to vertical tracking ( $\mathrm{F}(1$, $13)=11.3, p<.01)$, but this benefit was only in evidence when the tunnel was absent. The overlay had no influence on lateral tracking.

\section{SVS Traffic Surveillance}

The time required to detect and report traffic on the SVS display was shortened from 16 to 11 seconds when a tunnel was used $(\underline{\mathrm{F}}(1,13)=15.9, \underline{\mathrm{p}}<.01)$. Interestingly the tunnel's presence speeded traffic detection time more in VMC than in IMC $(\underline{F}$ interaction $=4.67, \underline{p}=.05)$. In contrast to the tunnel benefit, overlay imposed a significant 6 second cost to detecting traffic relative to the separated instrument panel $(\underline{F}(1,13)=34.9, \underline{p}<.01)$, presumably as a result of the clutter. Neither the guidance (tunnel) nor the overlay variable had any effect on the accuracy of traffic detection, nor on that of altitude change monitoring on the NAV display.

\section{Off-Normal Events}

Rogue aircraft detection. The small $\mathrm{N}$ for the detection of the single rogue aircraft in the outside world prevented traditional statistical analyses. However, it is important to note that 5 of 6 pilots $(83 \%)$ who experienced this event in the nontunnel (datalink) condition, responded with an appropriate evasive response, whereas in the tunnel condition, only 4 of 8 $(50 \%)$ did so. $($ Chi-squared $=2.67, \underline{p}=0.102)$.

Antenna detection. All pilots were able to notice the antenna, visible on the SVS display in all four conditions, and responded appropriately.

Runway offset. There was no difference between the overlay and separate conditions in responding to the runway offset, which was present only in the tunnel condition. Importantly, 5/12 pilots failed to notice the offset, and initiated their landing parallel to the true runway, rather than flying a missed approach.

\section{Visual scanning}

Analysis of how the different display conditions would influence the allocation of attention measured by percent dwell time (PDT) within the different areas of interest is shown in Figure 2. The data reveal the obvious dominance of the SVS panel (heavy black line) in all three display conditions in which the SVS panel hosted guidance information (the two tunnel conditions, and the overlaid instrument panel). A $2 \times 2 \times 2$ ANOVA was carried out on the PDT data for each area of interest.

On the right half of Figure 2, corresponding to displays in the right half of Figure 1, where the displays are separated (and hence visual attention allocation to the instrument panel can be discriminated from allocation to the tunnel and its SVS host), removing the tunnel substantially reduced attention to the SVS panel $(\underline{\mathrm{F}}(1,7)=705, \underline{\mathrm{p}}<.001)$ and such attention is re-allocated to the NAV display (guidance information for lateral tracking) and, particularly, to the instrument panel (vertical situation display for vertical tracking), as this reallocation is indicated by the increase in scanning to these areas of interest $(\underline{F}(1,7)=40 ; \underline{p}<.001 ; \underline{F}(1,7)=175, \underline{p}<.001$ respectively).

Figure 2 also reveals the decrease in SVS scanning and the increase in outside-world (OW) scanning associated with the outside visibility of $\operatorname{IMC}(\underline{\mathrm{F}}(1,7)=22.4, \underline{\mathrm{p}}<.01 ; \underline{\mathrm{F}}(1,7)=$ $14.5, \mathrm{p}<.01$, respectively). Not surprisingly, pilots look outside more often, when there is something to see. However it is noteworthy that even in the datalink separated VMC condition, when the SVS panel contains essentially the same information as the outside world, the former still receives over three times the amount of visual attention. It is a compelling source.

The scanning data suggest that the amount of visual attention drawn to the SVS display had little direct effect on 
the detection of traffic represented on that display. Had that been the case, then overlay in the datalink condition should have produced better traffic detection, not worse. Instead, SVS traffic detection appeared to be helped by the lower workload of flying with the tunnel (availing more resources for traffic surveillance) and hindered by the clutter of overlay. (Of course, in our research the tunnel was always placed on the SVS display where traffic was hosted. It would be interesting to see if detection performance is maintained when tunnel and SVS are separated).

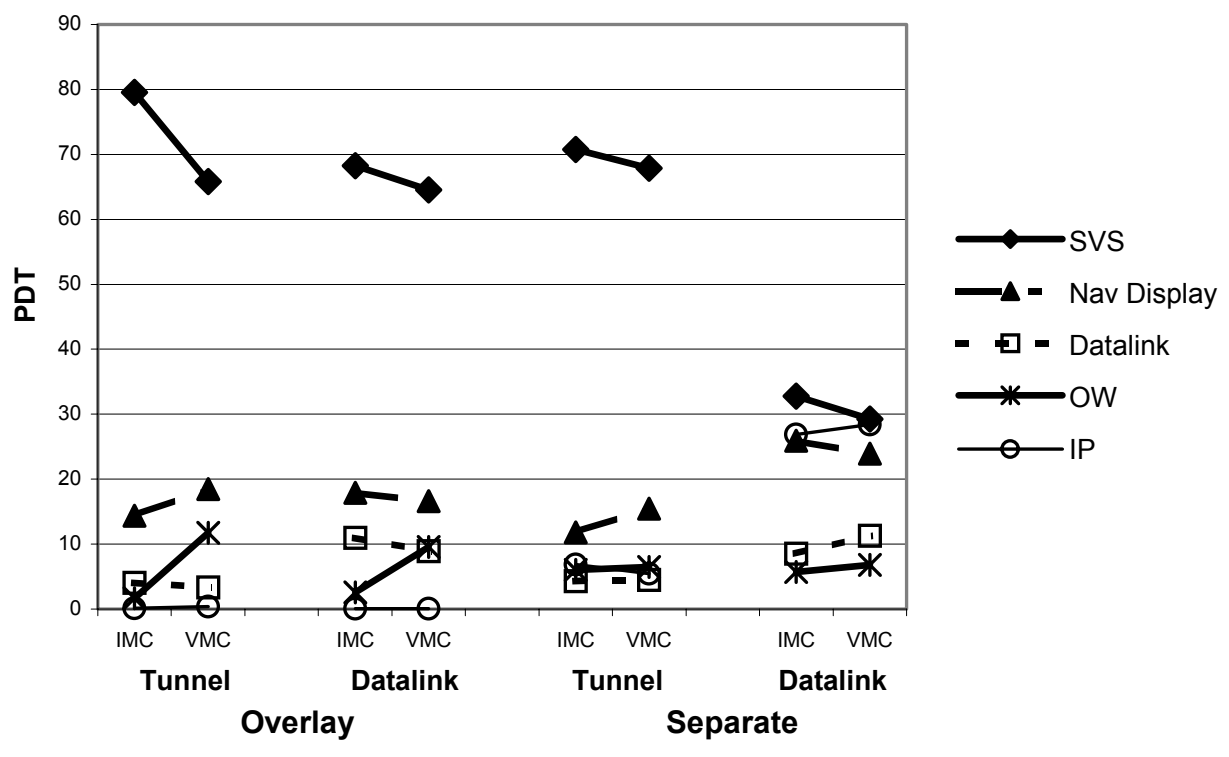

Figure 2: Percent dwell time on each area of interest (AOI) as a function of the 8 conditions.

The scanning data also allowed us to ask if the apparent finding of a cognitive tunneling effect described above (missed rogue airplane detection with the tunnel) was the result of a visual attention allocation away from the outside world, induced by the tunnel. The current data would seem to reject that hypothesis, since outside world scanning in VMC was relatively constant (around 9\%) between tunnel and datalink display conditions (see Figure 2).

The previous analysis reveals that certain display features induce scanning changes as well as performance changes. For example the tunnel draws the eyes to the SVS panel where it is hosted and increases flight path tracking performance. A final analysis was carried out as one means of addressing the question of whether the scanning differences were directly responsible for the performance changes. We asked this question via an individual differences analysis, examining the correlation between performance measures and scanning measures across the eight pilots who had both measures available.

First, we asked whether better flight path tracking was achieved by pilots who looked more at the source of flight path information - the SVS display in the tunnel conditions, and the SVS display (for attitude information), instrument panel (vertical situation)l, and map (lateral situation) in the non-tunnel conditions. The answer to this question was no. All correlations were low and non-significant. We accounted for these results by assuming that because flight path tracking was the primary task, all pilots did the necessary scanning to maintain performance at the optimal level. Pilots who needed to scan more (for example to the tunnel), did so, in a way to preserve their tracking performance at a level equal to those who needed to scan less. Second, we asked whether pilots who looked at the SVS display longer, detected the traffic hosted there more rapidly than those who looked at it less. Here, there was some modest support. Half of the correlations between scanning and detection RT were above a value of 0.40) and negative. However the aspect of scanning that was critical was not PDT, but was instead the mean dwell duration. Pilots who dwell longer on the SVS display, (rather than just visiting it more frequently) detect traffic more rapidly

\section{DISCUSSION}

The current research addressed several questions about the SVS display and the tunnel, two components often, but not necessarily, coupled in advanced avionics. First, the tunnel clearly aided performance, a finding that is by now well established. Flying was more accurate than with the guidance information availed in the datalink condition, distributed across the instrument panel and the map. Furthermore, resources freed by the tunnel display were used effectively to improve detection of traffic hosted at that same location; and the tunnel did not disrupt detection of traffic changes on the NAV display. Since all four display conditions (i.e., the datalink as well as the tunnel conditions) had an aircraft symbol and predictor (3D velocity vector) hosted in the SVS panel, it is apparent that the major advantage of the tunnel was 
in providing the $3 \mathrm{D}$ integrated preview of future commanded flightpath changes. In the datalink conditions, this preview was only available in 2D form, and only for lateral guidance, on the NAV display.

Second, the overlay of instrument panel information on the SVS display and designed to reduce scanning, offered little help, even when the tunnel was not present, and therefore the instrument panel information contained in the VSD was critical; furthermore, such overlay produced costs of clutter in detecting the low-visibility traffic symbols on the same display panel, a clutter cost of non-conformal instruments that is also well documented (Wickens et al., 2004).

Third, two aspects of the off-normal detection data provide some suggestion that the SVS tunnel system may induce some form of "cognitive tunneling". (1) As we noted, the tunnel produced a nearly-significant trend for a greater miss rate of the rogue aircraft visible only in the outside world. We cannot link this miss rate directly to a scanning deficit, since it was not tied to a lower percentage of scans to the outside world; it is possible that it may relate to a more "cognitive" attention allocation factor, induced by the tunnel. (2) Across both tunnel conditions, nearly half of the runway offsets (5/12) were missed. Like the rogues, these offsets could only be detected by outside world scanning. Whether this cognitive tunneling was the result of the flightpath tunnel, or simply the compelling SVS display with its visible but offset runway could not be ascertained from the current design, because the runway offset was only examined when the tunnel was present. Nevertheless, the fact that in all conditions, the SVS display availed very little outside world scanning ( $8 \%$ in VMC, only $4 \%$ in IMC), provides some reason for concern. Further insight into the possible sources of this cognitive tunneling is provided by Thomas and Wickens (2004).

\section{CONCLUSION}

The current results provide further evidence of the value of the tunnel, and the possible feasibility of using the SVS display to host forward traffic information. In considering this latter possibility, designers should keep in mind that SVS-hosted traffic may: (1) induce cognitive tunneling away from CDTI representations of traffic outside the GFOV of the SVS system (which could still be hazards), and (2) be obscured if the SVS platform hosts much overlaid instrument information.

\section{ACKNOWLEDGMENTS}

This research was supported by Grant \# NASA NAG 2-1535 (HPM-SWAP), from NASA Ames Research Center. Dr. David Foyle was the scientific technical monitor. The authors thank Roger Marsh, Ron Carbonari and Jonathan Sivier for their irreplaceable contributions in developing the SVS simulation used in the study.

\section{REFERENCES}

Alexander, A. L., Wickens, C. D., \& Hardy, T.J. (2003). Examining the effects of guidance symobology, display size, and field of view on flight performance and situation awareness. In Proceedings $47^{\text {th }}$ Annual Meeting of the Human Factors and Ergonomics Society. Santa Monica, CA: HFES.

Beringer, D. B. (2000). Development of highway-in-the-sky displays for flight-path guidance: History, performance, results, guidelines. Proceedings of the IEA 2000/HFES 2000 Congress. Santa Monica, CA.: HFES.

Fadden, S., Ververs, P. M., \& Wickens, C. D. (2001). Pathway HUDS: Are they viable? Human Factors, 43(2), 173-193.

Foyle, D. C., \& Hooey, B. L. (2003). Improving evaluation and system design through the use of off-nominal testing: A methodology for scenario development. Proceedings of the $12^{\text {th }}$ International Symposium on Aviation Psychology (pp. 397-402). Dayton, Ohio: Wright State Univ.

Kroft, P. \& Wickens, C.D. (2003) Displaying multi-domain graphical data base information. Information Design Journal 11(1) 44-52.

Merwin,D. (1998). Final report on HSCT External Vision System Traffic Symbology. Boeing Company Report.

Prinzel, L.J., Comstock, J.R., Glaab, L.J., Kramer, L.J., Arthur, J.J., \& Barry, J.S., (2004). The efficacy of head down and head up synthetic vision display concepts. International Journal of Aviation Psychology 14(1), 53-77.

Schnell, T., Kwon, Y., Merchant, S., \& Etherington, T. (2004). Improved flight technical performance in flight decks equipped with synthetic vision information system displays. International Journal of Aviation Psychology (14) 1, 79-102.

Thomas, L.C., \& Wickens, C.D. (2004). Eye-tracking and individual differences in unexpected event detection when flying with a Synthetic Vision System Display. In Proceedings $48^{\text {th }}$ Annual Meeting of the Human Factorand Ergonomics Society. Santa Monica, CA: HFES.

Wickens, C.D., Ververs, P.M., \& Fadden, S.F (2004). Head Up Displays. In D. Harris (Ed). Human Factors for Civil Aviation

Yeh, M., Merlo, J.L., Wickens, C.D., \& Brandenburg, D.L. (2003) Head up vs. head down. Human Factors, 45(4), 390-407. 